\title{
Recent Advances in Durability and Damage Tolerance Methodology at NASA Langley Research Center
}

\author{
J.B. Ransom ${ }^{*}$, E.H. Glaessgen ${ }^{\dagger}$ I.S. Raju ${ }^{\star}$ and C.E. Harris ${ }^{\infty}$ \\ NASA Langley Research Center, Hampton, Virginia, 23681, U.S.A.
}

\begin{abstract}
Durability and damage tolerance (D\&DT) issues are critical to the development of lighter, safer and more efficient aerospace vehicles. ${ }^{1}$ Durability is largely an economic life-cycle design consideration whereas damage tolerance directly addresses the structural airworthiness (safety) of the vehicle. Both D\&DT methodologies must address the deleterious effects of changes in material properties and the initiation and growth of damage that may occur during the vehicle's service lifetime. The result of unanticipated D\&DT response is often manifested in the form of catastrophic and potentially fatal accidents. As such, durability and damage tolerance requirements must be rigorously addressed for commercial transport aircraft and NASA spacecraft systems. This paper presents an overview of the recent and planned future research in durability and damage tolerance analytical and experimental methods for both metallic and composite aerospace structures at NASA Langley Research Center (LaRC).
\end{abstract}

\section{Introduction}

$\mathrm{D}$

URABILITY and damage tolerance issues have been a prominent consideration in aircraft design since several fatal accidents of De Havilland ${ }^{* *}$ Comets during the 1950's. Accidents and incidents resulting from fatigue and fracture continue to be an issue for the fleet and are a design consideration for future aircraft. Accident data from the National Transportation Safety Board (NTSB) using the Air Transport Association (ATA) coding system breaks down the cause of accidents (hardware malfunctions only) for 31 models of the 7571 transport airplanes registered in the United States from 1980-2001 as shown in Figure 1. ${ }^{2}$ The numbers on the $x$-axis in Figure 1 are component codes, which are explained in Figure 2.

Number of Occurrences

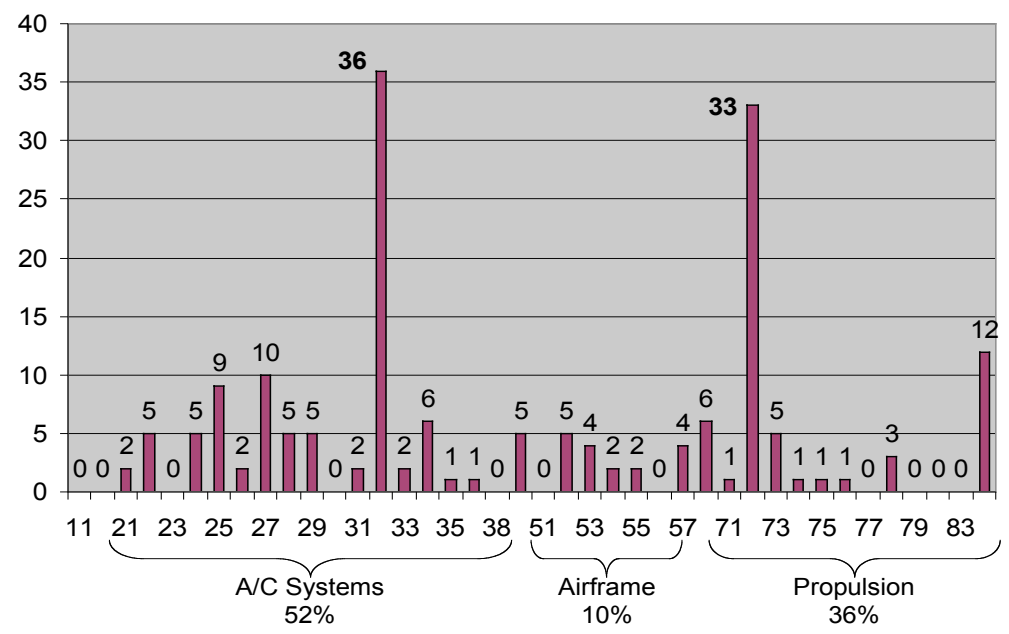

Figure 1: ATA Coded Breakdown of US Transport Airplane Accidents due to Mechanical Malfunctions

\footnotetext{
*Head, Durability, Damage Tolerance and Reliability Branch. Member AIAA

$\dagger$ Assistant Head, Durability, Damage Tolerance and Reliability Branch. Associate Fellow AIAA

* Structures Discipline Expert, NASA Engineering and Safety Center. Fellow AIAA

${ }^{\infty}$ Director, Research and Technology Directorate. Associate Fellow AIAA

** Trade names and trademarks are used in this paper for identification only. Their usage does not constitute an official endorsement, either expressed or implied, by the National Aeronautics and Space Administration. 


\begin{tabular}{|lll|}
\hline Aircraft Systems & Airframe & Propulsion \\
21: Air Conditioning & 51: Std. Practices/Structures & 71: Powerplant \\
22: Auto Flight & 52: Doors & 72: Turbine/Turboprop Engine \\
23: Communications & 53: Fuselage & 73: Engine Fuel \& Control \\
24: Electrical Power & 54: Nacelles/Pylons & 74: Ignition \\
25: Equipment/Furnishings & 55: Stabilizers & 75: Air \\
26: Fire Protection & 56: Windows & 76: Engine Control \\
27: Flight Controls & 57: Wings & 77: Engine Indicating \\
28: Fuel & & 78: Engine Exhaust \\
29: Hydraulic Power & & 79: Engine Oil \\
30: Ice/Rain Protection & & 80: Starting \\
31: Instruments & & 83: Accessory Gearboxes \\
32: Landing Gear & 85: Reciprocating Engine \\
33: Lights & \\
34: Navigation & & \\
35: Oxygen & & \\
36: Pneumatic & \\
38: Water/Waste & \\
& & \\
\hline
\end{tabular}

Figure 2: ATA Component Codes for US Airplane Accidents by Mechanical Causes

Of these accidents, those attributed to airframe structural failure are among the most catastrophic and potentially fatal. The unfortunate consequences of structural failure are well illustrated by several recent accidents investigated by the NTSB and are shown in Figure 3.

Figure 3(a) shows the forward fuselage section of an Aloha Airlines Boeing 737 shortly after separation of eighteen feet of fuselage above the passenger floor line and immediately aft of the cabin entrance door. ${ }^{3}$ Although the airframe had only 35,496 flight hours, the number of ground-air-ground cycles was much larger than might be expected because of the short duration of many of the aircraft's flights between the various Hawaiian islands. The cause of the Aloha Airlines accident was attributed to the linking of fatigue cracks emanating from fastener holes (multi-site fatigue damage). ${ }^{4}$

Figure 3(b) shows the vertical tail of American Airlines flight 587, an Airbus A300, as it was recovered from Jamaica Bay in New York. ${ }^{5}$ The cause of the American Airlines accident was determined to be the in-flight separation of the vertical tail as the result of loads beyond ultimate that were created by the first officer's unnecessary and excessive rudder pedal inputs. ${ }^{6}$ Analyses at NASA Langley Research Center showed that of the six attachment lugs that join the vertical tail and fuselage, the right rear lug failed first at a load of almost two times the design limit load (DLL). ${ }^{7}$

Figure 3(c) shows the right engine of a Delta Airlines flight 1288, a McDonnell Douglas MD-88, after the front compressor hub of the \#1 engine shattered and penetrated the left aft fuselage. ${ }^{8}$ The cause of the accident was final fracture of a fatigue crack growing from a manufacturing defect at a tie rod hole in the compressor hub. ${ }^{9}$

Figure 3(d) shows one of several tankers operated by the U.S. Forest Service that recently suffered catastrophic structural failures. ${ }^{10}$ In the case shown, both wings of a C-130A detached from the fuselage at their respective center wing box-to-fuselage attachment locations after the aircraft dropped its payload and began to arrest its decent and level out. Examination of the center wing box lower skin revealed that failure was caused by fast fracture of a 12-inch long fatigue crack that had not been detected during regular inspections. ${ }^{11}$ 


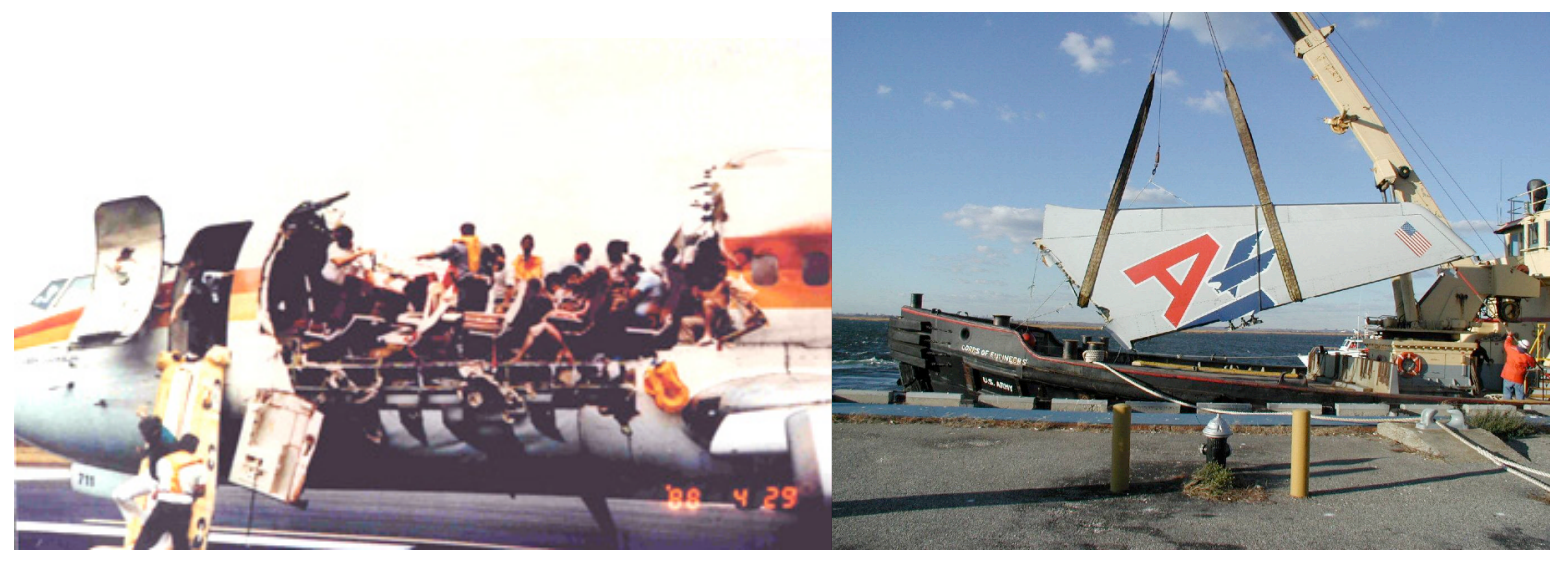

(a) Forward fuselage after Aloha Airlines accident ( 1 person killed)

(b) Recovery of Vertical Tail after American Airlines Flight 587 accident (265 people killed)

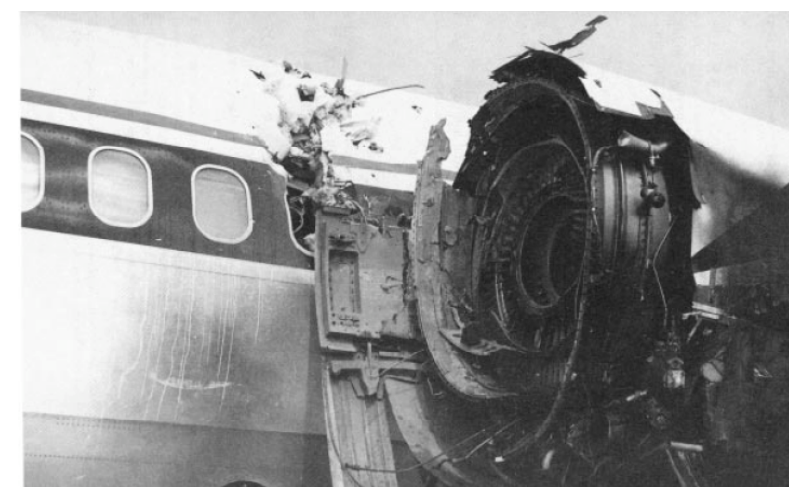

(c) Engine after Delta Flight 1288 accident ( 2 people killed)

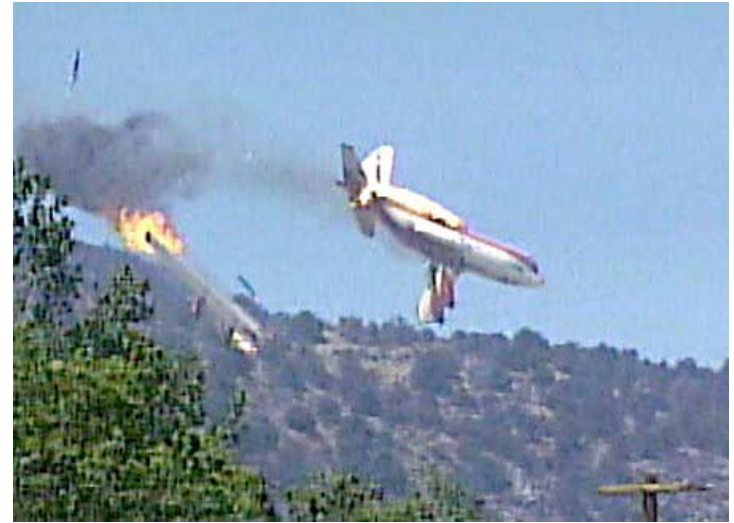

(d) U.S. Forest Service C-130 on June 17, 2002 near Walker, CA (3 people killed)

Figure 3: Several Recent Accidents

Although various extenuating circumstances contributed to each of these tragic accidents, in all four cases, the final failure resulted from accumulation and/or propagation of damage that reduced the load carrying capability of the structure to a level below what was needed to sustain structural loads. Tragedies such as these provide a strong moral and financial basis for the development of more accurate analytical and experimental methodologies for the prediction of damage initiation and growth.

This paper presents an overview of the recent and planned future research in durability and damage tolerance analytical and experimental methods for both metallic and composite aerospace structures at NASA Langley Research Center (LaRC). The current state-of-the-art in computational and experimental methods is illustrated via discussion of several recent NASA programs and failure investigations. Next, current and future research directions for continuum mechanics-based durability and damage tolerance for metallic and composite structures is discussed. Finally, recent advances and directions for damage science, the study of damage processes, in structural materials is presented. 


\section{Current and Future Research Directions}

To address the many issues that have been uncovered by accidents like those shown in Figure 3 and to develop improved durability and damage tolerance (D\&DT) methodologies for future vehicles, the Durability, Damage Tolerance and Reliability Branch (DDTRB ${ }^{*}$ ) at NASA Langley Research Center (LaRC) continues to develop durability and damage tolerance analytical and experimental methods for both metallic and composite aerospace structures. Figure 4 illustrates the progression of the Current State-of-the-Art, Emerging Continuum Methods and Damage Science. The Current State-of-the-Art consists of methods such as progressive failure analysis for composite materials and development of the fracture mechanics-based crack tip opening angle criterion used for metallic materials. Emerging Continuum Methods consist of development of advanced methods such as cohesive zone models for delamination modeling in composite materials and development of new interactive models for predicting fatigue crack closure in metallic materials. Finally, the work in Damage Science incorporates mechanics of materials, materials science and condensed matter physics to develop fundamental understanding of damage processes. While each of these areas merits its own development, a significant advantage can be achieved by integrating research between adjacent levels. The remainder of this section discusses recent and on-going work within the Durability, Damage Tolerance and Reliability Branch at NASA LaRC in each of these levels in more detail.

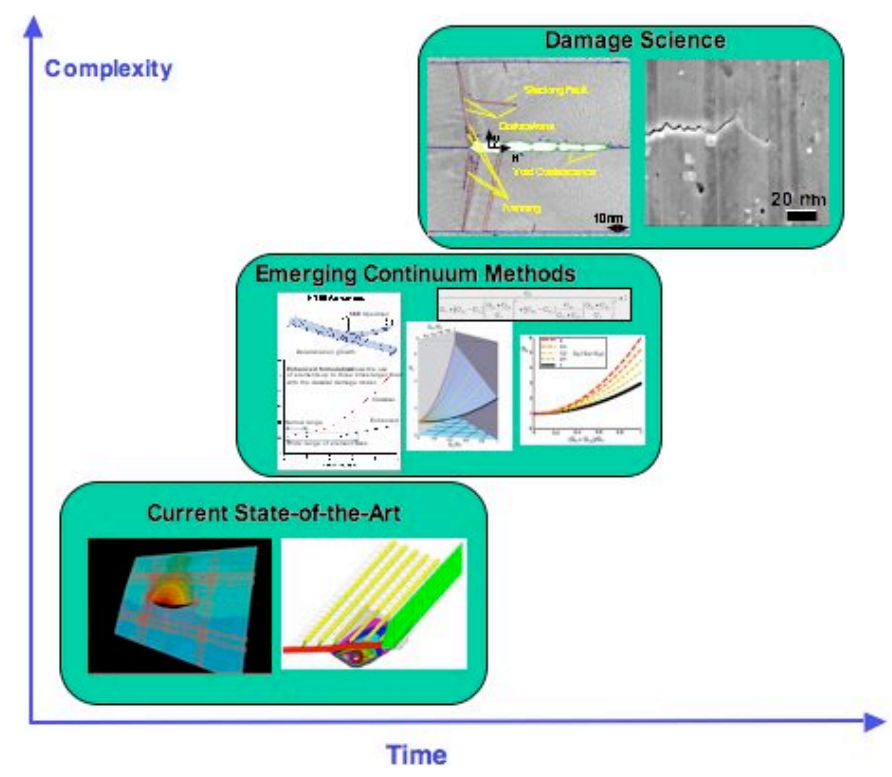

Figure 4: Current and Future Research Directions

\section{Current State-of-the-Art}

Within DDTRB, the Current State-of-the-Art in computational and experimental methods is represented by on-going work in elastic-plastic fracture and widespread fatigue damage in metallic skin-stiffened fuselage panels ${ }^{4,12}$ and in characterization of advanced composite material forms and the progressive failure analysis (PFA) of a composite skin-stiffened vertical stabilizer lug.?

As part of the Aircraft Structural Integrity Program (ASIP), an analytical methodology was developed for predicting the onset of widespread fatigue damage (WFD) in fuselage structure. ${ }^{4}$ The determination of the aircraft service life that is related to the onset of WFD includes analyses for crack initiation, fatigue crack growth and residual strength. Carefully conducted teardown examinations of aircraft components indicated that WFD behavior can be represented by the following three analysis scales: 1) small three-dimensional cracks at the microstructural

* DDTRB will be used herein to represent the current branch as well as its predecessor organizations at LaRC

(e.g., Mechanics of Materials Branch) American Institute of Aeronautics and Astronautics 
level, 2) through-the-thickness two-dimensional cracks at the local structural level, and 3) long cracks at the global structural level. Therefore, the computational capability required to predict analytically the onset of WFD included analyses to predict the growth of cracks over a wide range of sizes, from the material (microscale) level to the global (structural scale) level. ${ }^{4}$

Several codes for the prediction of stress intensity factors, crack propagation and fatigue crack growth were funded entirely or in part by DDTRB ${ }^{*}$ during ASIP. Among these are ZIP3D, FRANC3D, STAGS and FASTRAN II. The ZIP3D computer code was developed to model three-dimensional crack configurations and to calculate the corresponding stress-intensity factors. ${ }^{13}$ The FRANC3D code also has solid modeling capabilities for threedimensional configurations and can adaptively remesh the configuration as the crack grows. ${ }^{14,15}$ The STAGS finite element code was interfaced with FRANC3D to develop a flexible computational platform for predicting crack growth in cylindrical stiffened shells. ${ }^{16}$ Stress-intensity-factor solutions are used as input data for the FASTRAN II code to predict fatigue crack growth. The FASTRAN II code is based on the mechanics of plasticity induced crack closure. The effects of prior loading history on fatigue behavior, such as crack-growth retardation and acceleration, are computed on a cycle-by-cycle basis. The code will predict the growth of cracks exhibiting the small-crack effect, as well as of two- and three-dimensional cracks exhibiting the classical Paris law crack-growth behavior. ${ }^{17}$ Other codes, such as NASGRO ${ }^{18}$, a general-purpose damage tolerance analysis code developed at NASA Johnson Space Center, have been developed in collaboration with DDTRB.

Additionally, crack tip opening angle (CTOA) was developed as a criterion for crack growth (see Figure 5 ) and used in conjunction with the various finite element analyses to predict growth of existing flaws within a skin-stiffened panel. ${ }^{19-22}$ The CTOA criterion assumes that a crack will stably tear when the angle made by the crack faces reaches a critical value some distance behind the crack tip, $d$, as determined by coupon tests (e.g., compact tension, center notch tension). The relationship between CTOA and crack tip opening displacement (CTOD) is also shown in Figure 5. During ASIP, crack tip plasticity, three-dimensional constraints around the crack tip, crack tunneling, slant crack growth, and crack growth through sections of varying thickness were all considered. ${ }^{19-22}$ Recent research directions include modeling the crack branching process followed as a lead crack enters an integrally-stiffened region, crack growth through sections of reinforced material, and implications of cyclic crack tip opening displacement $(\triangle \mathrm{CTOD})$ in fatigue life estimation.
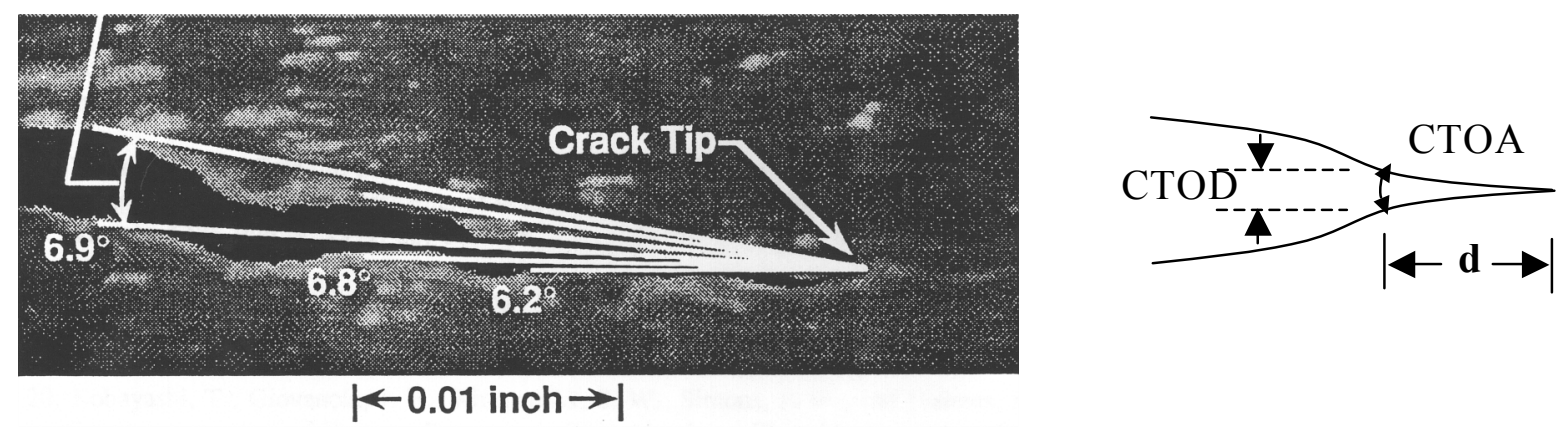

Figure 5: Illustration of Crack Tip Opening Angle (CTOA) Fracture Criterion

During the same time period as ASIP, the NASA Advanced Composites Technology Program (ACT) spearheaded many analytical and experimental, as well as manufacturing, developments for composite materials. The ACT program was undertaken in three phases. Phase A focused on identification and evaluation of innovative manufacturing technologies and structural concepts. During Phase B, the most promising of these technologies and concepts were matured. Finally, during Phase C, a full scale stitched and resin-film infused composite wing box was manufactured, analyzed and tested as shown in Figure 6.

One of the more far-reaching outcomes of the ACT program (1989-1999), was the DDTRB-led development of various technologies for the analytical and experimental interrogation of the failure mechanics, damage tolerance and residual strength of textile-based composites. ${ }^{23,24}$ Issues such as the effects of manufacturing variations in textile preform architecture for stitched, woven and braided textiles were considered by more than 20 contributors from academia, industry and the government. ${ }^{23}$ 


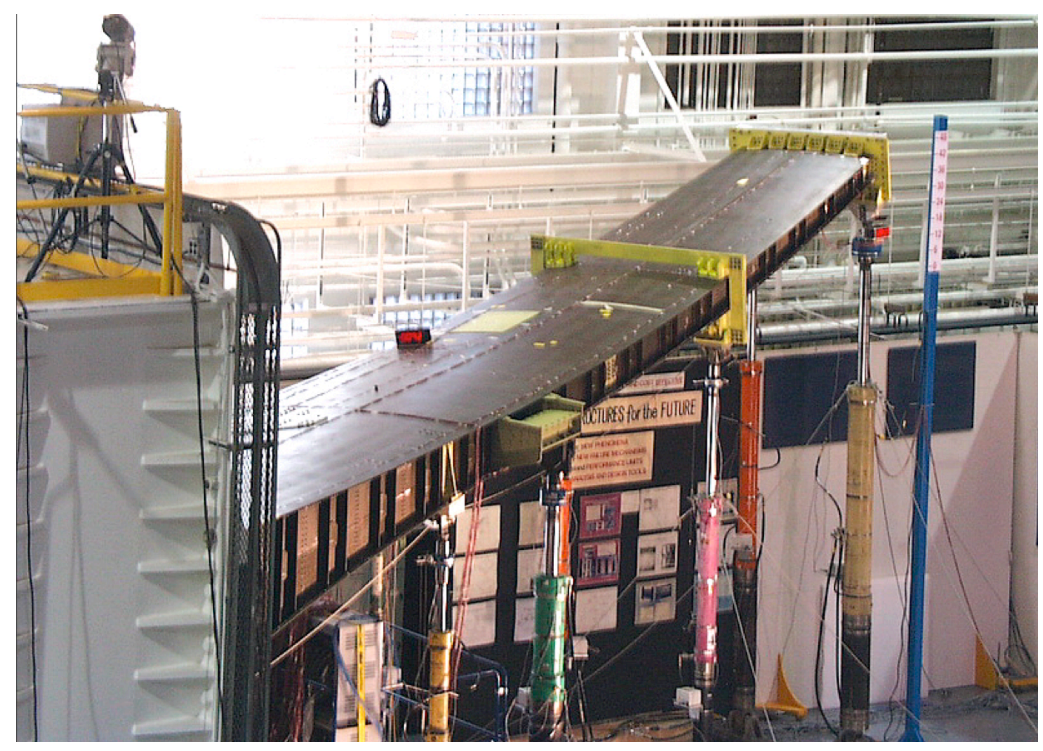

Figure 6: Ultimate Load Test of Stitched/Resin Film Infused Composite Wingbox

Additionally, numerous failure and incident investigations have provided important opportunities to apply state-of-the-art research methods to solve important engineering problems. As a part of NASA LaRC's support of the National Transportation Safety Board's investigation of the American Airlines flight 587 accident, DDTRB research staff modified a continuum progressive failure analysis, that was originally developed as part of the ACT program, to predict failure of the aircraft's laminated composite lugs. ${ }^{7}$

The loads experienced by the first of the six attachment lugs that failed (the right rear lug), allowing the vertical tail to separate from the fuselage, were evaluated using global models of the vertical tail, local models near the lug, and a global-local analysis procedure. The progressive failure analysis (PFA) was implemented to determine the load, mode, and location of failure of the right rear lug under loading representative of an Airbus certification test conducted in 1985, three subcomponent tests conducted as part of the investigation in 2003, and the accident condition. For the accident condition, the predicted failure load for the right rear lug from the PFA was determined to be greater than 1.98 times the limit load of the lug.
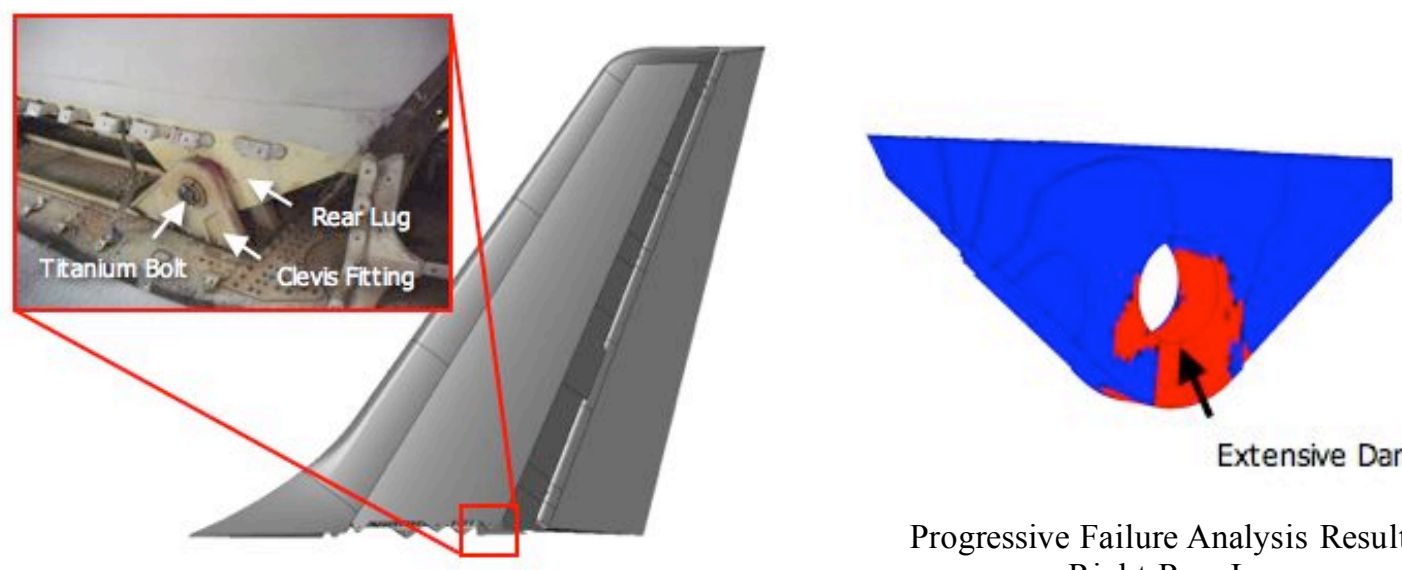

Extensive Damage

Progressive Failure Analysis Results - Right Rear Lug

Figure 7: Laminated Composite Lug Failure on AA flight 587 
Another tool that has been extensively developed during NASA research programs and implemented to support a recent failure investigation, is the virtual crack closure technique (VCCT). Originally published in 1977, the method has undergone extensive development throughout the community, including DDTRB. ${ }^{25}$ When the X-33 sandwich-composite liquid hydrogen (LH2) tank failed during a protoflight structural proof test in November 1999 as shown in Figure 8, a team of engineers and support personnel, representing NASA and its contractors, was called on to support the investigation. Figure 9 is a plot of calculated mode I strain energy release rate $\left(G_{I}\right)$ versus internal pressure within the honeycomb sandwich core of the tank wall. The internal pressure resulted from cryopumping of LH2 into the sandwich followed by an expansion of the hydrogen from the liquid to the gaseous phase as the tank warmed after being drained.

Also seen in Figure 9 are the mean, lowest measured and lowest statistically possible core-to-facesheet bondline toughness $\left(G_{c r}\right)$ as determined by single cantilever tests. Because the foreign object debris (FOD) crossed the cells of the honeycomb core as shown in the insert in the figure, making it impossible to determine the debond width, $G$-values were computed for three "effective" widths as shown in the figure. The VCCT-based fracture mechanics analyses showed that a combination of internal core pressure, low core to facesheet toughness and a Teflon tape FOD at the bondline, were the likely cause of the failure. ${ }^{1,26,27}$
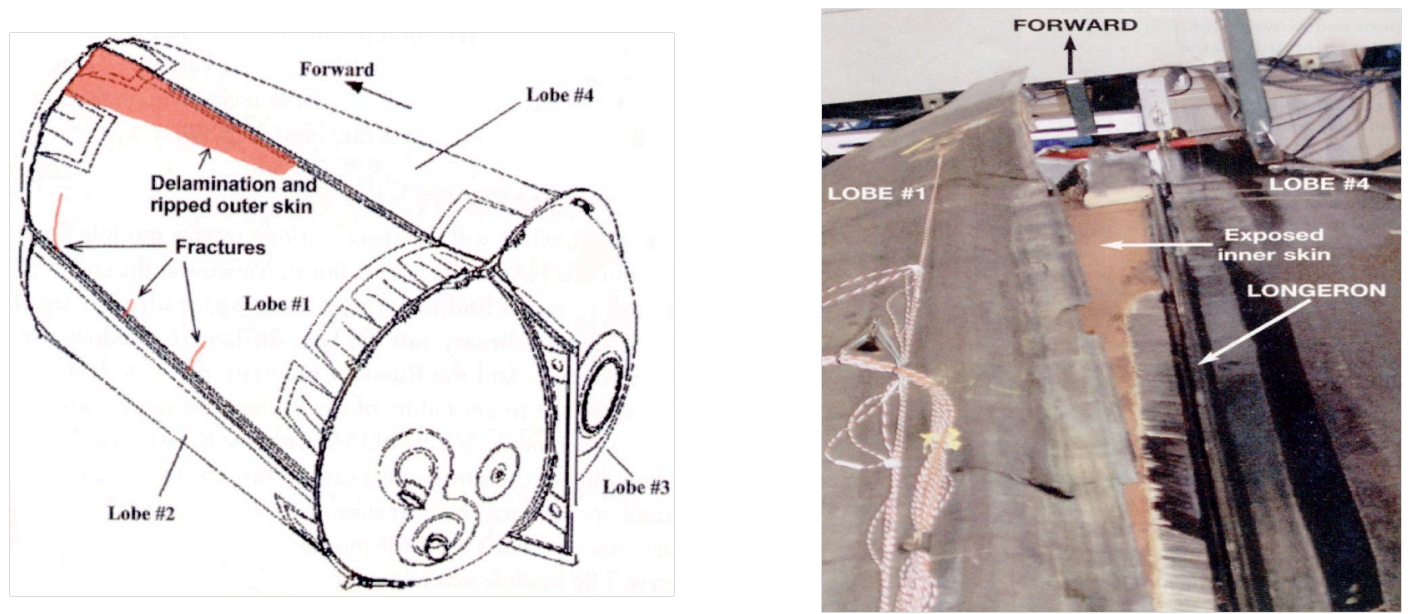

Figure 8: Failure of X-33 Sandwich-Composite Liquid Hydrogen Tank

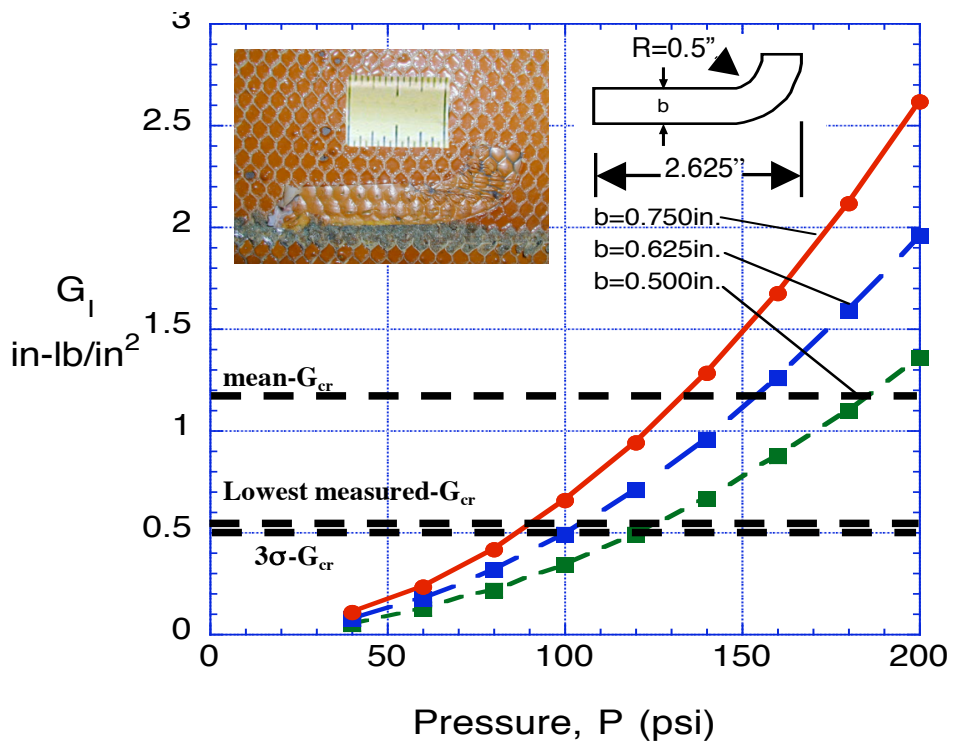

Figure 9: Fracture Mechanics Prediction of Delamination Growth in X-33 LH2 Tank 


\section{Emerging Continuum Methods}

Although these methods, that have been developed for the prediction of fracture and failure of metallic and composite materials, have met with considerable success, they often contain many more assumptions and simplifications than are desired for rigorous analysis. Additionally, new material forms and applications are mandating innovation. As a result, more accurate analyses and more realistic testing methods are needed. Thus, Emerging Continuum Methods are being developed to more thoroughly understand and predict failures. Within DDTRB, new criteria are being developed and evaluated to more accurately predict initiation and propagation of cracks and other forms of damage in metallic and composite materials. Additionally, new analytical and experimental methods are being developed to predict and interrogate damage growth in these structural materials under conditions representative of both aircraft and spacecraft flight. In the remainder of this section, several current topics of research in durability and damage tolerance of metallic and composite materials, will be discussed.

\section{Fatigue Crack Closure Modeling in Metallic Materials ${ }^{28,29}$}

Although it is widely acknowledged that crack path and crack-wake roughness are strongly affected by the local alloy microstructure, the specific microstructural configurations that result in high crack closure and fatigue resistance are not well understood. An advanced crack closure model has been developed that includes closure contributions from the three closure mechansims considered to be most influential near the fatigue crack growth threshold: plasticity-, roughness-, and oxide-induced crack closure. This model, referred to as the CROP model (Closure, Roughness, Oxide, and Plasticity), considers the interactions between these mechanisms and also includes the effects of out-of plane cracking and multi-axial loading. These features make the CROP closure model uniquely suited for, but not limited to, threshold applications. Rough cracks are idealized as two-dimensional sawtooths as shown in Figure 10, whose geometry induces mixed-mode crack tip stresses. Continuum mechanics and crack-tip dislocation concepts are combined to relate crack face displacements to crack-tip loads. Geometric criteria are used to determine closure loads from crack-face displacements. Finite element results, used to verify model predictions, provide critical information about the locations where crack closure occurs.

This analytical model has been validated with experimental results determined from local (i.e., near cracktip) and global compliance data, as shown in Figure 10. Here, $R_{c l}$ is the closure ratio and is equal to the closure load, $K_{c l}$, normalized by $K_{\max }\left(K_{c l} / K_{\max }\right)$. Also shown in Figure 10 is the corresponding $d a / d N$-versus- $\Delta K$ data that shows the correlation between increasing closure ratio and the onset of fatigue crack growth threshold. The model has been shown to accurately predict near-threshold crack closure behavior - a product of local microstructure - though it does not yet include a physical relation between microstructure and crack path.

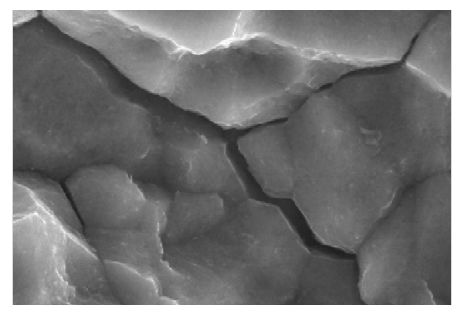

Crack Wake Roughness

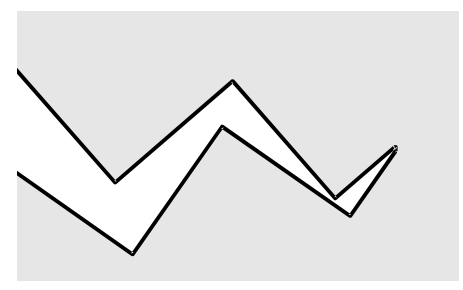

2-D Approximation
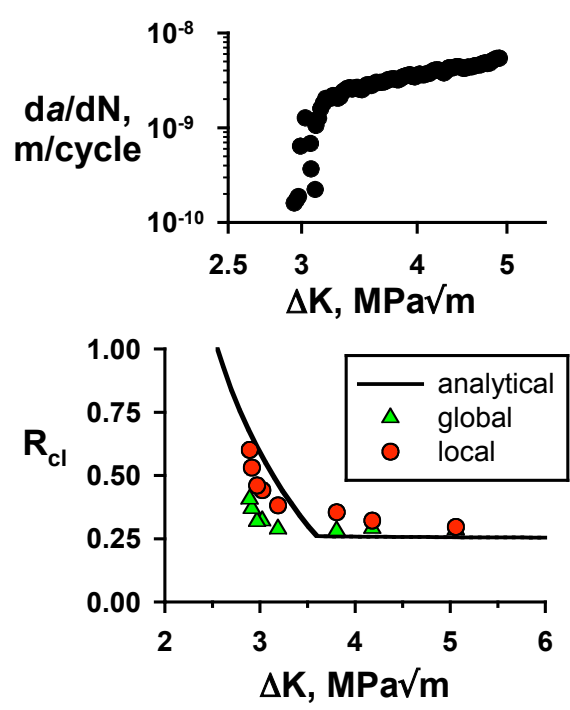

CROP Model Predictions

Figure 10: Plasticity, Roughness \& Oxide Induced Crack Closure 
Three Dimensional Constraint Effects on $\triangle C T O D^{30}$

The variation in lateral constraint through the specimen thickness has an effect on the estimated cyclic crack-tip-opening displacement $(\Delta \mathrm{CTOD})$. This effect directly influences the calculated fatigue threshold level for various thickness specimens tested under different load reduction procedures. The $\triangle \mathrm{CTOD}$ is a valuable measure of crack growth behavior, indicating closure development, constraint variations and load history effects. Variable amplitude loading with a continual load reduction was used to simulate the load history associated with fatigue crack growth threshold measurements. The constraint effect on the estimated $\triangle \mathrm{CTOD}$ was studied by carrying out three-dimensional elastic-plastic finite element simulations. The analysis involves numerical simulation of different standard fatigue threshold test schemes to determine how each test scheme effects $\triangle$ CTOD. The American Society for Testing and Materials (ASTM) recommended standard load reduction procedures for threshold testing were simulated with both the constant stress ratio $(R)$ and constant maximum stress intensity $\left(K_{\max }\right)$ methods.

Numerical estimates of $\triangle \mathrm{CTOD}$ were carried out using three-dimensional elastic-plastic finite element analyses for both middle crack tension, $\mathrm{M}(\mathrm{T})$, and compact tension, $\mathrm{C}(\mathrm{T})$, specimens. The analyses confirmed the existence of discontinuous, three-dimensional crack closure for both $\mathrm{M}(\mathrm{T})$ and $\mathrm{C}(\mathrm{T})$ specimens under the constant $R$ load reduction procedure. The analyses also indicated that the amount of remote crack closure estimated in the near threshold region is primarily dependent upon the initial value of stress intensity factor range, $\Delta K_{o}$, chosen for the constant $R$ load reduction procedure. In contrast, under the constant $K_{\max }$ loading, no crack closure was observed in the threshold region.

The variation in local $\triangle \mathrm{CTOD}$ and crack closure levels for a 7075-T73 Aluminum $\mathrm{C}(\mathrm{T})$ specimen under the constant $R=0.1$ load reduction procedure with an initial $\Delta K_{o}$ of $15 \mathrm{MPa} \sqrt{\mathrm{m}}$ are shown in Figure 11 . The specimen was $12.7 \mathrm{~mm}$ thick with a $76.2 \mathrm{~mm}$ width ( $W$, measured from the point of load application). Curves of local $\triangle \mathrm{CTOD}$ and crack closure levels are given at three through thickness positions (surface $(6.35 \mathrm{~m}), 4.4 \mathrm{~mm}$ and mid-surface $(0.0 \mathrm{~mm})$ ). In Figure 11, the local closure quantities, indicated by the red lines, are calculated at one node, or 10 microns, behind the current crack tip location, while the $\triangle$ CTOD values, indicated by the black lines, are calculated at $0.01 \mathrm{~mm}$ behind the crack tip location. The estimated $\triangle \mathrm{CTOD}$ values through the thickness decrease during the constant $R$ load reduction procedure (i.e., as $\Delta K$ applied is decreased). At higher applied $\Delta K$, $\triangle \mathrm{CTOD}$ is observed to vary through the thickness; however, as the applied $\Delta K$ value decreases below a value of approximately $5 \mathrm{MPa} \sqrt{\mathrm{m}}$, the variation in $\triangle \mathrm{CTOD}$ through the thickness is negligible. During this load reduction, local crack closure levels on the outer surface decrease from the steady state value of 0.38 computed at the initial $\Delta K_{o}$ of $15 \mathrm{MPa} \sqrt{\mathrm{m}}$. For applied $\Delta K$ values less than $7 \mathrm{MPa} \sqrt{\mathrm{m}}$, locally, the crack remains fully open through the thickness of the specimen. With further reduction in applied $\Delta K$ to the near threshold region, the estimated $\triangle \mathrm{CTOD}$ value decreases while the crack remains fully open locally.
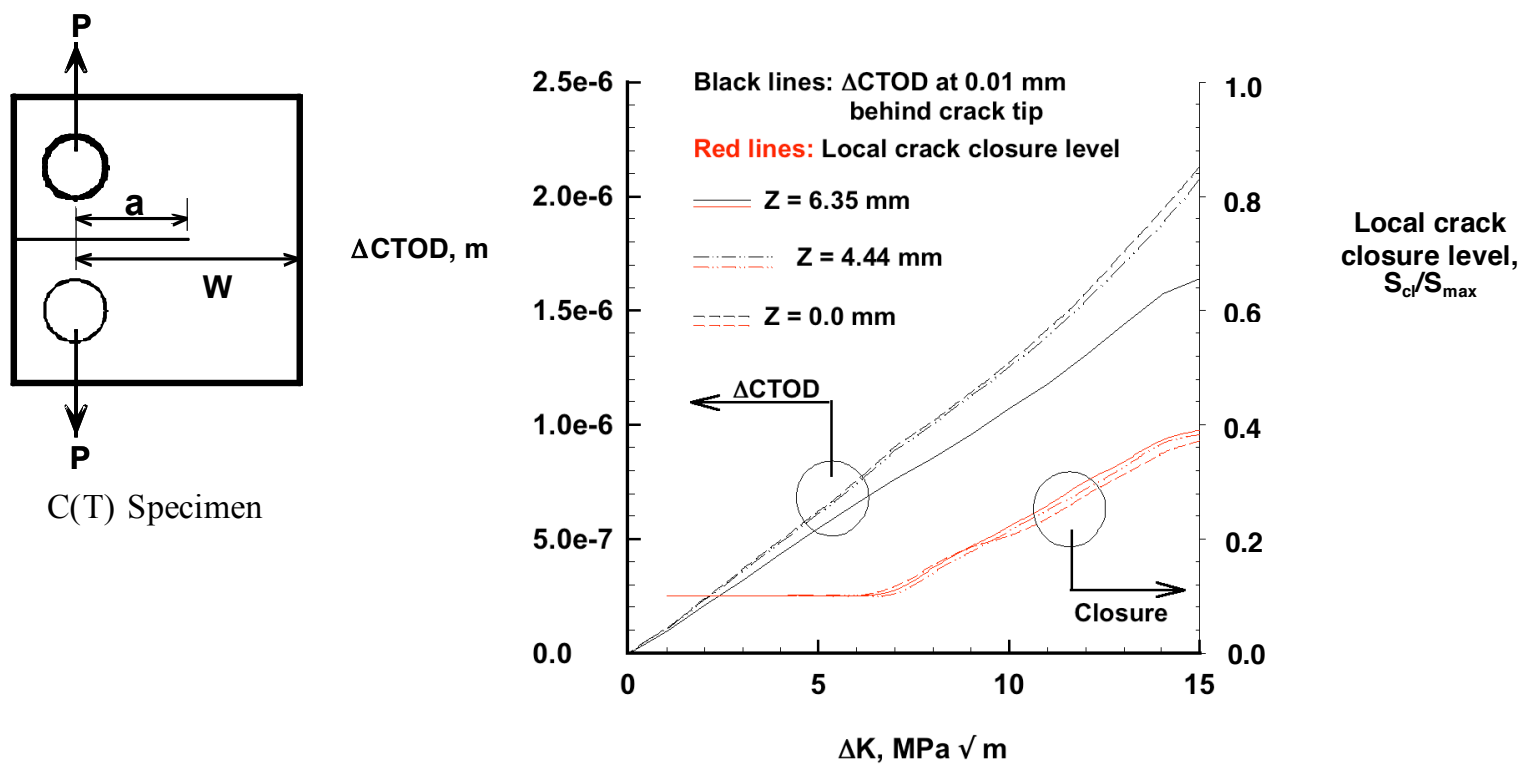

$\mathrm{C}(\mathrm{T})$ Specimen

Figure 11: Variation in local $\triangle \mathrm{CTOD}$ with applied constant $\mathrm{R}$ load reduction procedure at three through thickness positions (surface $(6.35 \mathrm{~mm})$, intermediate $(4.4 \mathrm{~mm})$ and mid-surface $(0.0 \mathrm{~mm}))$ 
Recently, the aircraft industry has begun to consider development of integrally-stiffened metallic structures as a successor to traditional riveted skin-stiffened structures with the goals of reducing part count and manufacturing cost. The CTOA methodology that was developed for predicting fracture characteristics, damage tolerance and residual strength of riveted aircraft structures, is being extended to predict residual strength of these new integrallystiffened metallic structures. The residual strength predictions for a $1220-\mathrm{mm}$ wide curved integrally-stiffened aluminum panel and a $508-\mathrm{mm}$ wide integrally-stiffened aluminum panel were within $3 \%$ and $2 \%$ percent of test failure loads, respectively.

Figure 12 is an overview of the CTOA-based prediction methodology for integrally-stiffened metallic structures. As in traditional fracture mechanics-based approaches, the fracture parameter (CTOA, $\Psi_{c}$, in this case) is determined from standard compact tension or center notch tension tests and then, assuming similitude, used to predict fracture of the built-up structures. The CTOA parameters were calibrated using the test data and then used for the finite element calculations of the larger panels. With the success in the fracture analyses of cracked built-up and integrally-stiffened panels, the finite-element software and CTOA fracture criterion is becoming a useful tool for the fracture design and analysis of integrally-stiffened thin and thick structures.
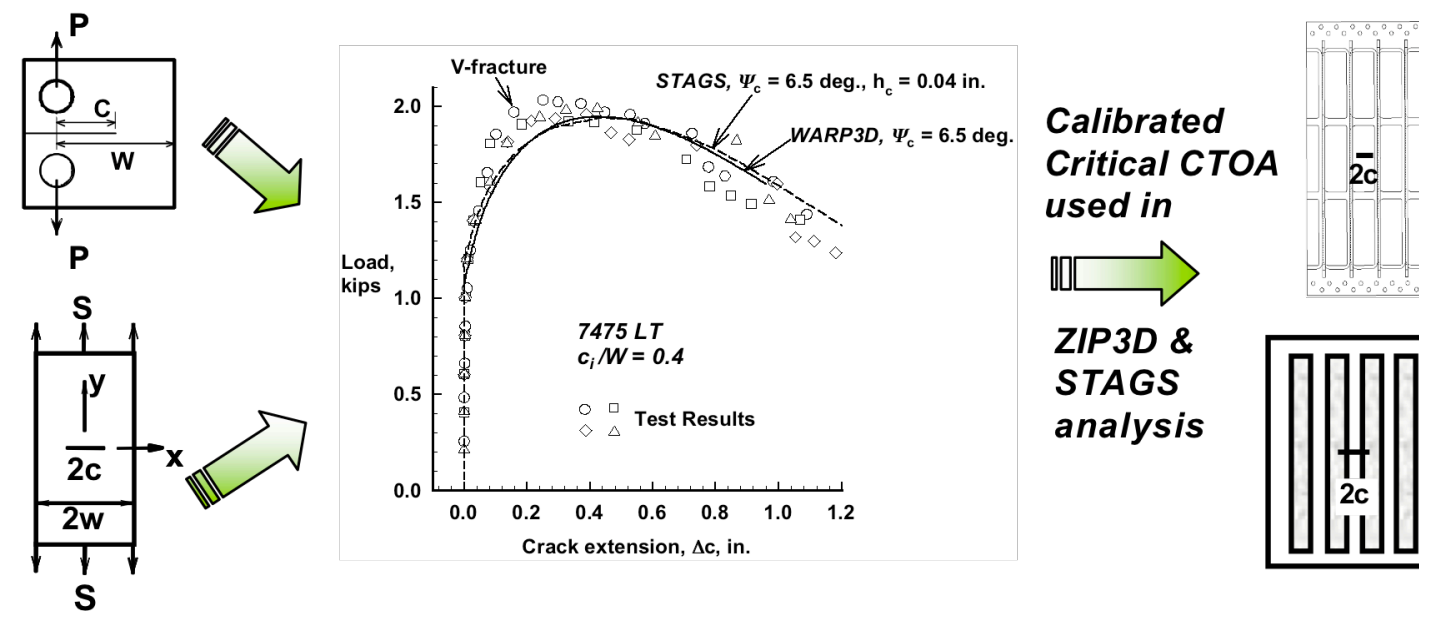

Figure 12: Residual Strength Prediction Methodology for Integrally-Stiffened Metallic Panels

Delamination Growth Assessment for Laminated Composites - Skin-Stiffened Panels ${ }^{32-34}$

Many composite components in aerospace structures are made of flat or curved panels with co-cured or adhesively bonded frames and stiffeners. Testing of skin-gage stiffened panels designed for use in pressurized aircraft fuselage has shown that delamination-induced bond failure at the tip of the frame flange is an important and very likely failure mode. ${ }^{35}$ Interlaminar fracture mechanics has been proven useful for characterizing the onset of such delaminations in composites. It has been used primarily to investigate delamination onset in fracture toughness specimens and laboratory-size coupon type specimens. Future acceptance of the methodology by industry and certification authorities however, requires the successful demonstration of the methodology on a structural level. Thus, a composite stringer-reinforced panel loaded in shear was analyzed.

The applied shear loading causes the panel to buckle, and the resulting out-of-plane deformations initiate skin/stringer separation at the location of an embedded defect. Defects in a range from $81.9 \mathrm{~mm}$ to $355.6 \mathrm{~mm}$ long were considered at the center stringer of a $1016 \mathrm{~mm}$ by $1016 \mathrm{~mm}$ panel as shown in Figure 13. In the finite element analysis, the panel and surrounding load fixture were modeled with shell elements as shown in Figures 13a and 13b. A small section of the stringer foot and the panel in the vicinity of the embedded defect were modeled with a local 3D solid model. A failure index was calculated by correlating computed mixed-mode strain energy release rates with the mixed-mode failure criterion of the carbon/epoxy material. Computed failure indices were in good agreement with results from models where the entire delaminated section of the stiffener foot had been modeled with 
solid elements. An example result for an $81.9 \mathrm{~mm}$ long delamination is shown in Figure 13c. The study confirmed that the local 3D solid model did not have to include the entire delaminated section. Thus, the use of a smaller local 3D solid model was shown to reduce model size without compromising the computed failure indices.
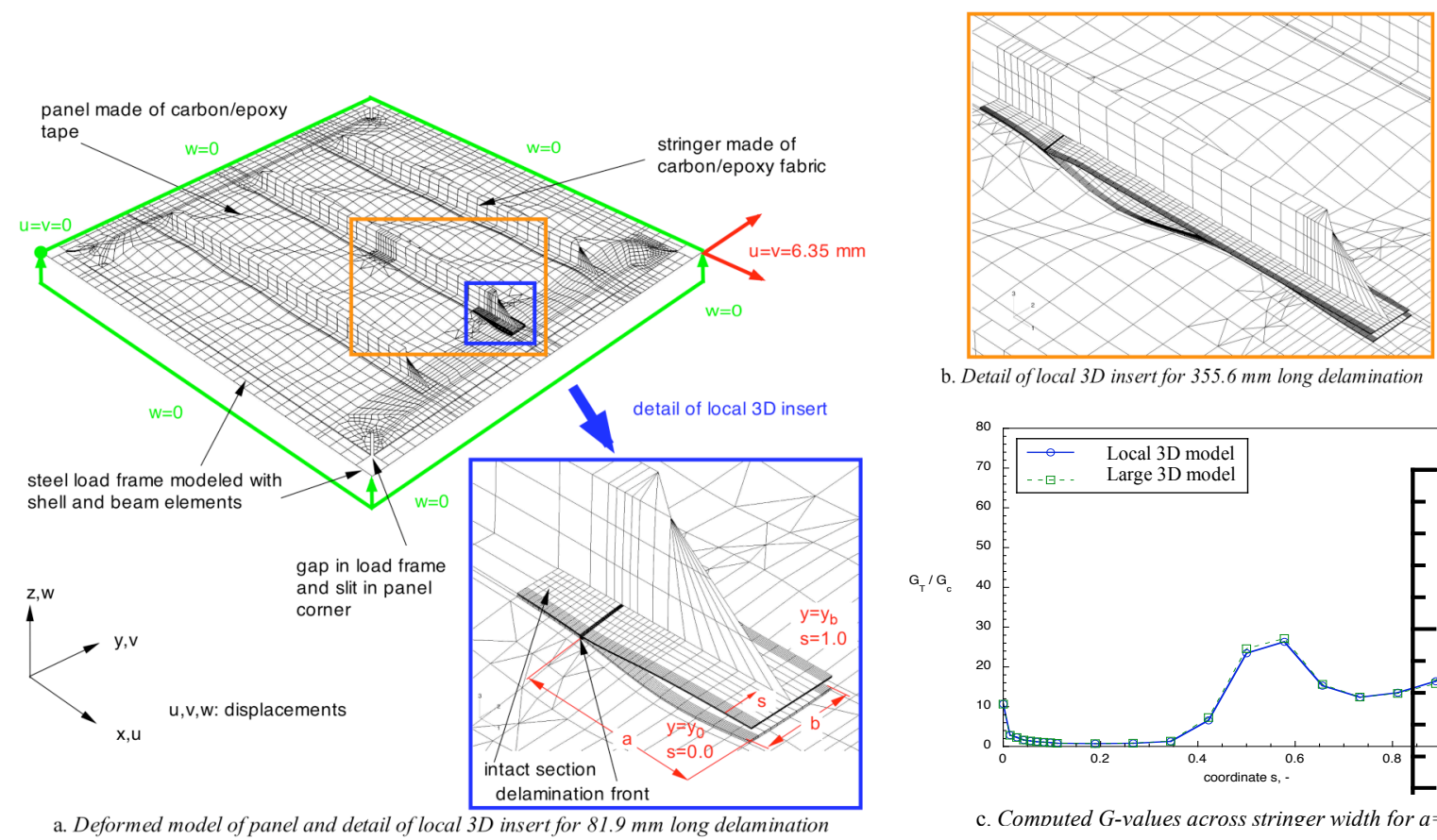

b. Detail of local $3 D$ insert for $355.6 \mathrm{~mm}$ long delamination

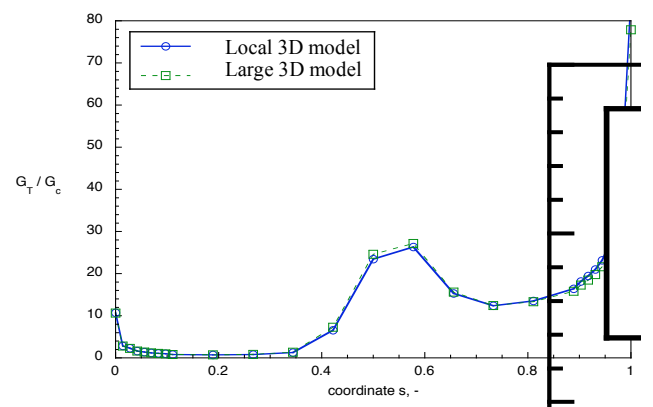

c. Computed $G$-values across stringer width for $a=81.9 \mathrm{~mm}$

Figure 13: Finite Element Model for Delamination Growth Assessment in Skin-Stiffened Panel

Fatigue Life Methodology for Tapered Hybrid Composite Flexbeams ${ }^{36}$

Polymeric composites are used to manufacture hingeless, bearingless composite rotor hubs for helicopters. These components are made of fewer parts and offer the advantages of reduced weight and drag, compared to metal hubs. During flight, these rotor hubs experience constant axial tension load from the centrifugal forces, and transverse bending in the flapping flexure region. In order to accommodate bending loads, composite flexbeams use internal ply-drops to create a nonlinear taper. However, these internal ply-drops create material and geometric discontinuities, which are sources of delamination onset. Tests of tapered laminates showed that delaminations tended to start at the tips of terminated plies at locations near the surface of the flexbeams (see Figure 14). An analysis and test methodology that incorporates damage, failure initiation and growth, and failure probability has been developed to demonstrate reliability for new and existing rotor hub designs.

All of the tested specimens failed by delaminations first starting as a crack between the tip of the ply drop group and the adjacent resin region, and growing at the interfaces around the dropped ply toward the thick region of the flexbeam. Delaminations grew with increasing number of cyclic loads, and new delaminations formed at other ply-drop locations. A 2-D finite element model was developed representative of the flexbeam geometry, boundary conditions, and loading. The model was analyzed using two commercially available finite element computer programs, ANSYS $^{\circledR}$ and ABAQUS ${ }^{\circledR}$. Delaminations of various lengths were simulated in the analytical model by releasing multipoint constraints (MPCs). Strain energy release rates $(G)$ were calculated using the virtual crack closure technique (VCCT) using both finite element programs. The calculated peak $G$-values were used with material characterization data to calculate fatigue life curves, for comparison with test data. An automated digital camera system was used to detect delamination onset in the flexbeams. The study showed that delaminations originate at a ply-drop near the surface (ply drop 311) and grow toward the thick end of the flexbeam. With continued cycling, delaminations initiate and grow at other ply-drops (e.g., ply drop 111), but these delaminations do not cause catastrophic failure of the flexbeam. 

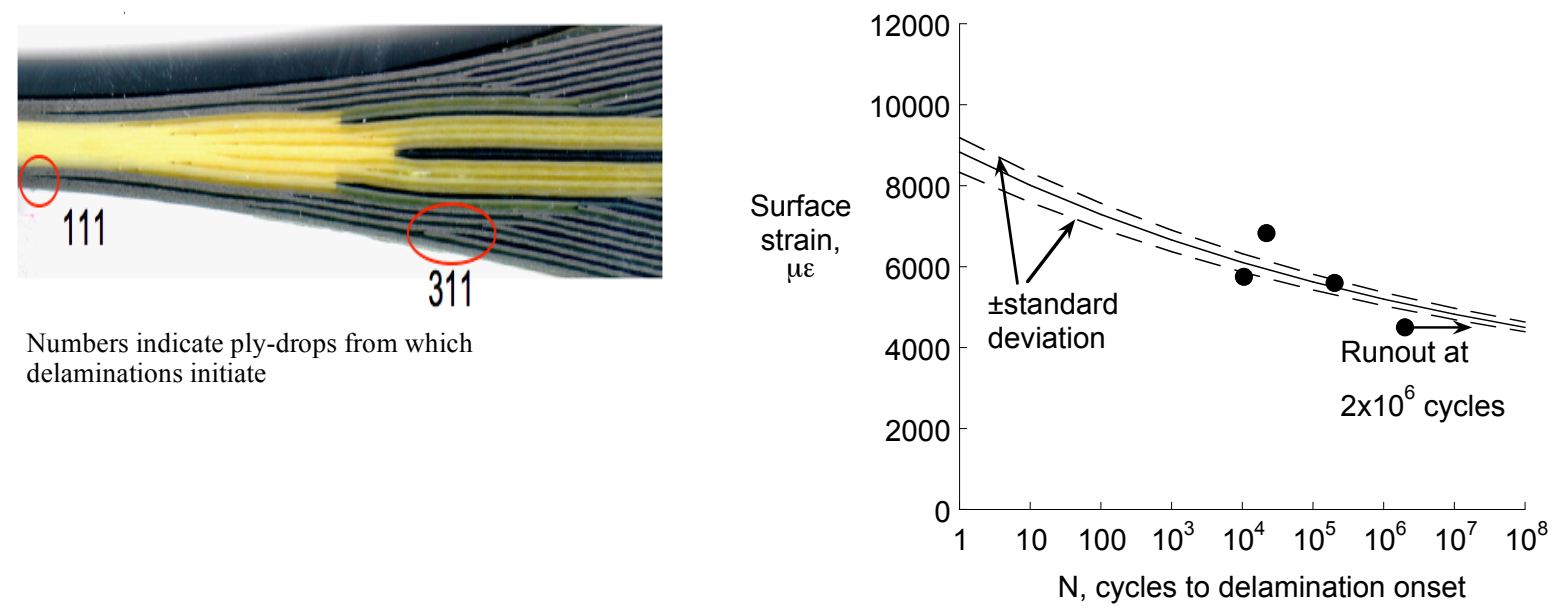

Figure 14: Calculated and Measured Delamination Onset for Glass Midplane (GLMS) Flexbeams

\section{Interactive Delamination Criterion $^{37}$}

Recently, many advances have been made in finite element modeling of delamination growth, however, a critical, yet incompletely developed aspect of the modeling techniques is the criterion used to determine when a delamination will grow under arbitrary mixed-mode conditions. Usually, this criterion involves a critical strain energy release rate that depends on some combination of mode I, mode II and mode III loading. Currently, test methods exist for determination of delamination growth for pure mode I, pure mode II and pure mode III loadings, as well as mixed mode I and mode II loading. However, there is no accepted way to measure the delamination fracture toughness when an arbitrary combination of all three modes (mode I, mode II and mode III) is present. As a result, there is not an accepted fracture criterion that considers all three modes.

Development of fracture criteria in the past was greatly influenced by the manner in which the toughness data was either reduced or presented. To avoid such shortcomings, a more rigorous framework for development of 3D fracture criteria has been proposed. As a result, a new 3D fracture criterion, shown in Figure 15, was introduced and is based on a $2 \mathrm{D}$ fracture criterion ${ }^{38}$ that has been shown to accurately model a wide range of materials in the mode I-mode II region. The new criterion is based on the supposition that the relationship between mode I and mode III toughness is similar to the relation between mode I and mode II toughness and that a linear interpolation can be used between mode II and mode III. The three-dimensional representation of the criterion along with a twodimensional projection are shown for the specific case of $G_{I C}=1 \mathrm{in} .-1 \mathrm{~b} . / \mathrm{in} .{ }^{2}, G_{I I C}=3 \mathrm{in} .-1 \mathrm{~b} . / \mathrm{in}^{2}, G_{I I I C}=6 \mathrm{in} .-1 \mathrm{~b} . / \mathrm{in}^{2}$, $\eta=2$. A proper evaluation of the new criterion is still pending until mixed-mode fracture tests are developed that incorporate a mode III component of loading.

$$
\frac{G_{T}}{G_{I c}+\left(\left(G_{I I c}-G_{I c}\right) \frac{G_{I I}}{G_{T}}+\left(G_{I I I}-G_{I c}\right) \frac{G_{I I I}}{G_{T}}\right)\left(\frac{G_{I I}+G_{I I I}}{G_{T}}\right)^{\eta-1}} \geq 1
$$

New 3D Delamination Criterion 


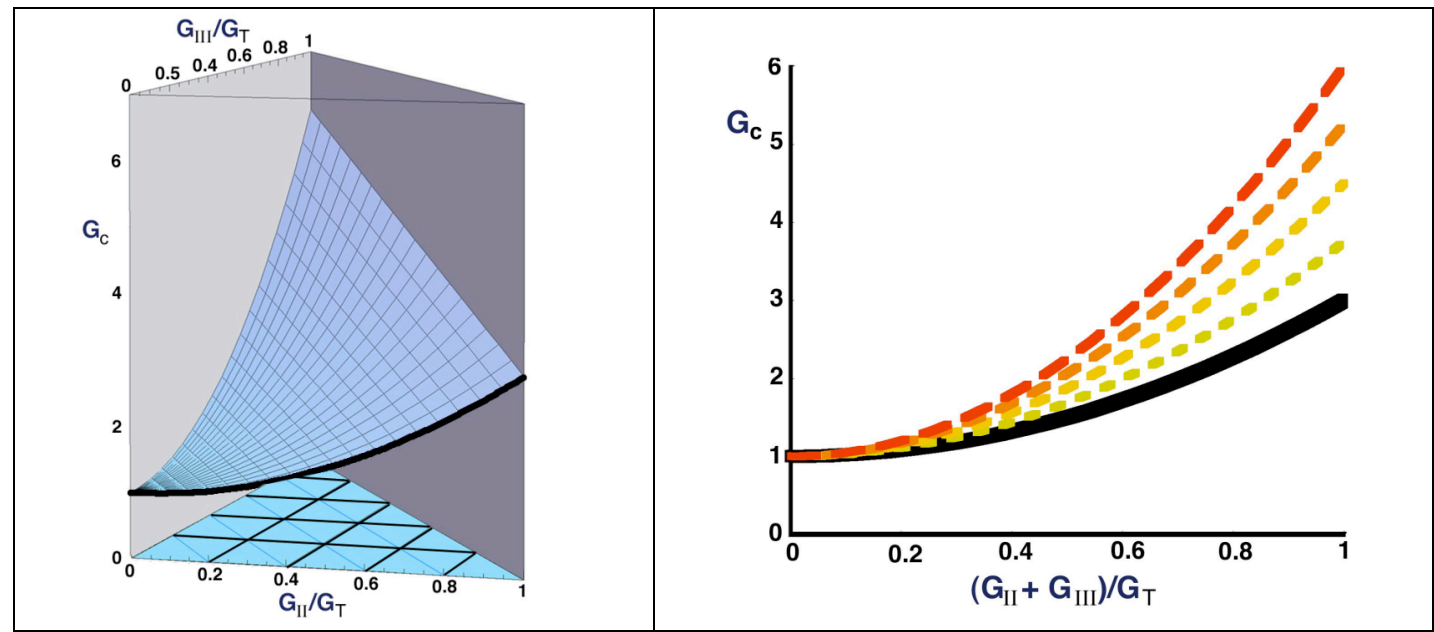

Figure 15: New 3D Delamination Criterion with $\mathrm{G}_{\mathrm{IC}}=1, \mathrm{G}_{\mathrm{IIC}}=3, \mathrm{G}_{\mathrm{IIIC}}=6, \eta=2$

\section{Progressive Failure Analysis for Composite Materials ${ }^{7,39,40}$}

Progressive Failure Analysis (PFA) can be used to predict the initiation and the propagation of damage while taking into account the internal load redistributions caused by the evolution of that damage. The methodology has been developed over the past two decades and has been successfully implemented in many practical contexts? but because of the needs of improving accuracy, modeling various complex failure modes and consideration of new materials and material architectures, it remains a very active topic of research.

User-defined PFA material models for laminated composite materials and structures are being developed. The material models are suitable for interrogation of traditional and bi-modulus orthotropic materials. Progressive failure analysis options have been developed for different point-stress methods with various failure initiation and material degradation models. These models have been implemented within an UMAT subroutine and are executed using the ABAQUS/Standard nonlinear finite element tool.

Various material failure models have been considered, including Maximum Stress, Maximum Strain, Tsai$\mathrm{Wu}$ and Hashin failure initiation criteria. ${ }^{39}$ Material degradation is achieved through a set of degradation factors dependent on whether the failure mode is tension, compression or shear driven and is applied to the material stiffness coefficients rather than the elastic engineering mechanical properties to maintain symmetry in the local material stiffness matrix. Material degradation can be applied instantaneously or recursively in the ply-discounting models. Recursive degradation in combination with fractional degradation factors is found to provide reliable progressive failure solutions. For material systems that exhibit nonlinear stress-strain behavior in the pre-ultimate regime, strain-based failure initiation models have been recommended. Alternatively, continuum damage mechanics models, such as the Matzenmiller (MLT) model, are advocated to represent nonlinear pre-ultimate and post-ultimate material response. ${ }^{39}$

Figure 16 shows a typical result of a progressive failure analysis of a laminated carbon/epoxy composite open hole tension (OHT) configuration. ${ }^{39}$ The configuration is 9-in. long and 1-in. wide with 16-plies of $\mathrm{T} 300 \mathrm{H} / 3900-2$ carbon/epoxy $\left(t_{p l y}=0.00645 \mathrm{in}\right)$ and a stacking sequence of $\left[(0 / 90)_{4}\right]$ and contains a 0.25 -in diameter circular hole at its centroid. The predictions using four failure criteria along with the experimentally determined value for the failure load $\left(9,605 \mathrm{lb}^{41}\right)$ are shown in the figure. The influence of different PFA assumptions on the predicted response is discussed further in Ref. 39. 


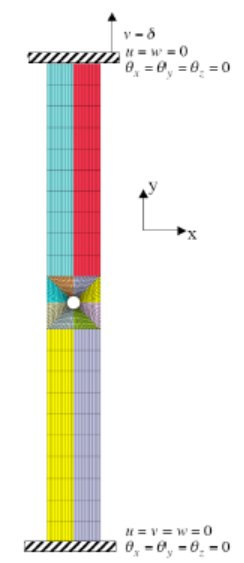

Finite Element Model of Open Hole Tension (OHT) Configuration

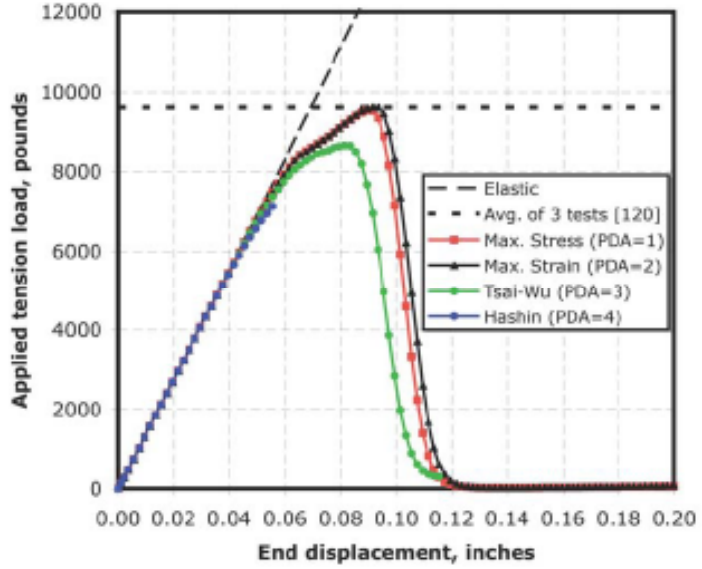

PFA Results for 16-ply Cross-Ply OHT

Figure 16: Comparison of Results of Progressive Failure Analysis with Different Failure Models ${ }^{39}$

Compression Strength Testing and Prediction for Impact-Damaged Sandwich Composites ${ }^{42}$

Sandwich construction is an efficient means of providing structural components with high bending stiffness relative to their overall weight. The interaction, however, between the stiff facesheet and low-density core results in numerous possible failure modes such as core crushing, facesheet wrinkling, and facesheet/core debonding. Characterizing the performance of sandwich structures is further complicated when damage is introduced into the facesheet material. Of particular interest, is the residual compression strength of sandwich structure containing lowvelocity impact damage on one of the facesheets.

A technique was tailored to predict the residual compression strength of specimens that exhibit a kink-band propagation failure mode, where kink bands are formed at the peak-strain locations adjacent to the impact damage region (see Figure 17). Under continued compression loading, the kink bands propagate in a stable manner perpendicular to the applied load. When a critical kink-band length is reached, growth becomes unstable and results in panel failure. The prediction method involved an analysis that modeled the impact-damaged sandwich specimen as a single facesheet with an open hole. The method was undertaken in two stages, each representing stages of failure that were observed in testing. For stable kink-band growth, the average stress criterion was used to calculate the far-field stress corresponding to a range of virtual kink-band lengths. Unstable kink band growth was assumed to take place when the strain energy stored at the kink-band tip reached the fracture toughness of the facesheet.

Fracture tests were conducted on sandwich specimens to measure the facesheet fracture toughness. Linear elastic fracture mechanics (LEFM) was then used to calculate the far-field stress required for unstable kink-band growth. Stress values corresponding to stable and unstable kink-band growth were plotted as functions of kinkband length. The intersection of the curves was assumed to correspond to panel failure, yielding a prediction of residual compression strength. The method was calibrated against residual compression strength values of impactdamaged sandwich panels available in the literature. The sensitivity of the predicted residual strength to the scatter in measured facesheet fracture toughness values was found to be small. Each predicted strength value (calculated over two standard deviations of fracture toughness values) were conservative estimates of the measured strengths. 

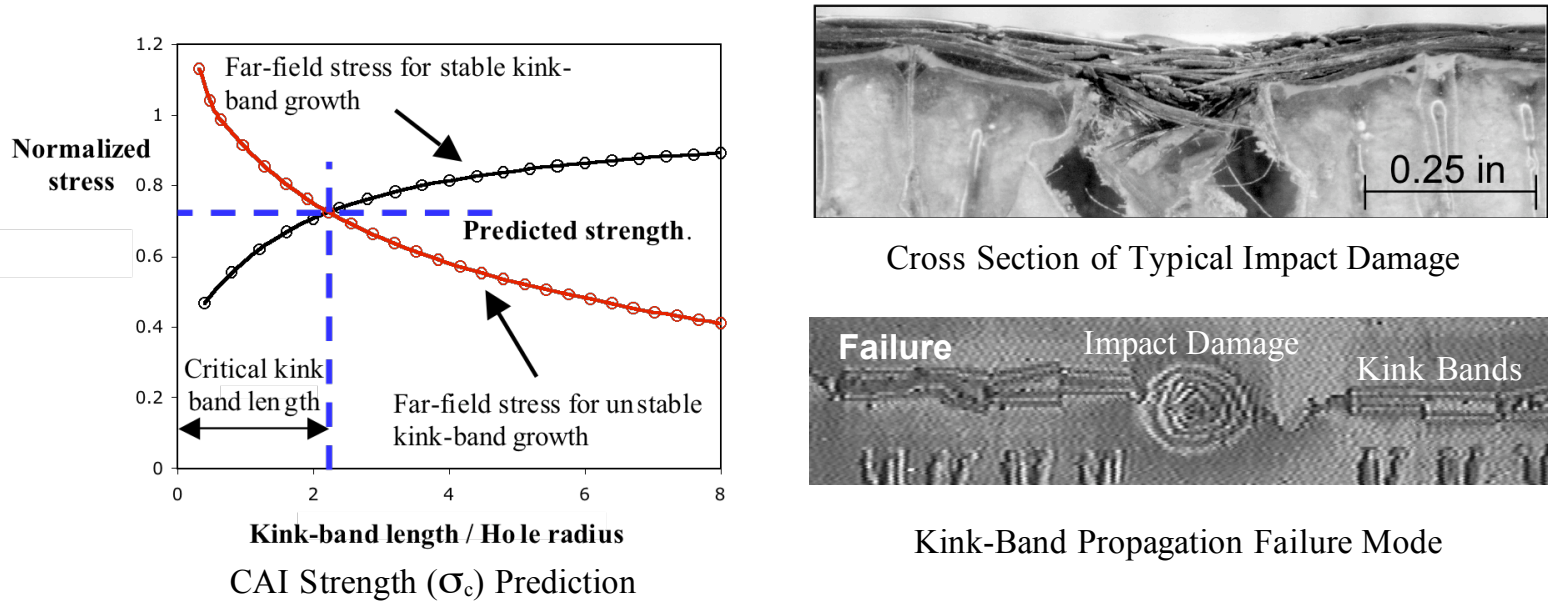

Cross Section of Typical Impact Damage

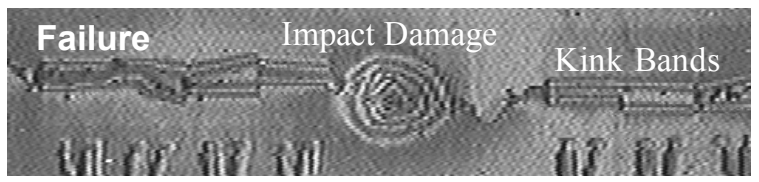

Kink-Band Propagation Failure Mode

Figure 17: Impact Damage Characterization for Sandwich Composites

\section{Damage Science}

To supplement the efforts in Emerging Continuum Methods, computational and experimental Damage Science methodologies are being developed to facilitate the understanding of durability and damage tolerance at a very fundamental level. ${ }^{43}$ Computational damage science tools include molecular dynamics simulation, dislocation dynamics, polycrystalline plasticity and grain-scale finite element analysis. Experimental damage science tools include scanning electron microscopes (SEM), environmental scanning electron microscopes (ESEM) and fracture surface topography analysis (FRASTA).

\section{Computational Damage Science $e^{43}$}

Molecular dynamics (MD) simulation is used to determine the fundamental processes of damage initiation and growth including plastic mechanisms (e.g., twinning, dislocations, stacking faults) and the creation of free surfaces (i.e., crack propagation). Both simultaneous and sequential multiscale methods are being developed to augment the capabilities of the molecular dynamics simulations. The simultaneous multiscale methods are developed to dramatically improve computational efficiency by virtually embedding a small (several million atom) MD simulation within a large finite element model. The sequential multiscale methods are developed to extract fundamental constitutive relationships from the $\mathrm{MD}$ and embed them within grain-scale finite element micromechanics analyses.

In the example shown in Figure 18, a traction-displacement relationship that may be embedded into a cohesive zone model for microscale problems of intergranular fracture is extracted from atomistic molecular-dynamics simulations. ${ }^{43}$ A molecular-dynamics model for crack propagation under steady-state conditions was developed to analyze intergranular fracture along a flat $\Sigma 99\left[\begin{array}{lll}1 & 1 & 0\end{array}\right]$ symmetric tilt grain boundary in aluminum. Under hydrostatic tensile load, the simulation reveals asymmetric crack propagation in the two opposite directions along the grain boundary. In one direction, the crack propagates in a brittle manner by cleavage with very little or no dislocation emission, and in the other direction, the propagation is ductile through the mechanism of deformation twinning. This behavior is consistent with the Rice criterion for cleavage vs. dislocation blunting transition at the crack tip. The preference for twinning to dislocation slip is in agreement with the predictions of the Tadmor and Hai criterion. ${ }^{44}$ A comparison with finite element calculations showed that while the stress field around the brittle crack tip follows the expected elastic solution for the given boundary conditions of the model, the stress field around the twinning crack tip has a strong plastic contribution.

The results of an MD simulation for a nano-scale crack loaded with 4.25 GPa hydrostatic stress is shown in the figure. Common neighbor analysis (CNA) is used to identify atoms in different crystallographic states: fcc (in gray), hep (in red), and non-crystalline atoms (in blue). Atoms missing more than 1/3 of their nearest neighbors are 
identified as surface atoms (in green). Thus, a number of different formations are considered as follows: (1) - GB interface; (2) - twin boundary; (3) - core of a partial or twinning dislocation; (4) - nanovoid at the crack tip; (5) - slip dislocation; (6) - GB dislocation; and (7) - secondary slip. Note that (5) is not shown in this figure.

Through the definition of a Cohesive-Zone-Volume-Element - an atomistic analog to a continuum cohesive zone model element - the results from the molecular-dynamics simulation are recast to obtain an average continuum traction-displacement relationship, $\sigma_{y y}^{s}$ vs. $\lambda$, where $\sigma_{y y}^{s}$ is the traction normal to the crack plane and $\lambda$ is the corresponding opening displacement. The work of decohesion, $\Gamma$, is also shown in the figure. These values can be used to represent cohesive zone processes along the grain boundary interface for the cases of either ductile or brittle fracture at the nano-scale.
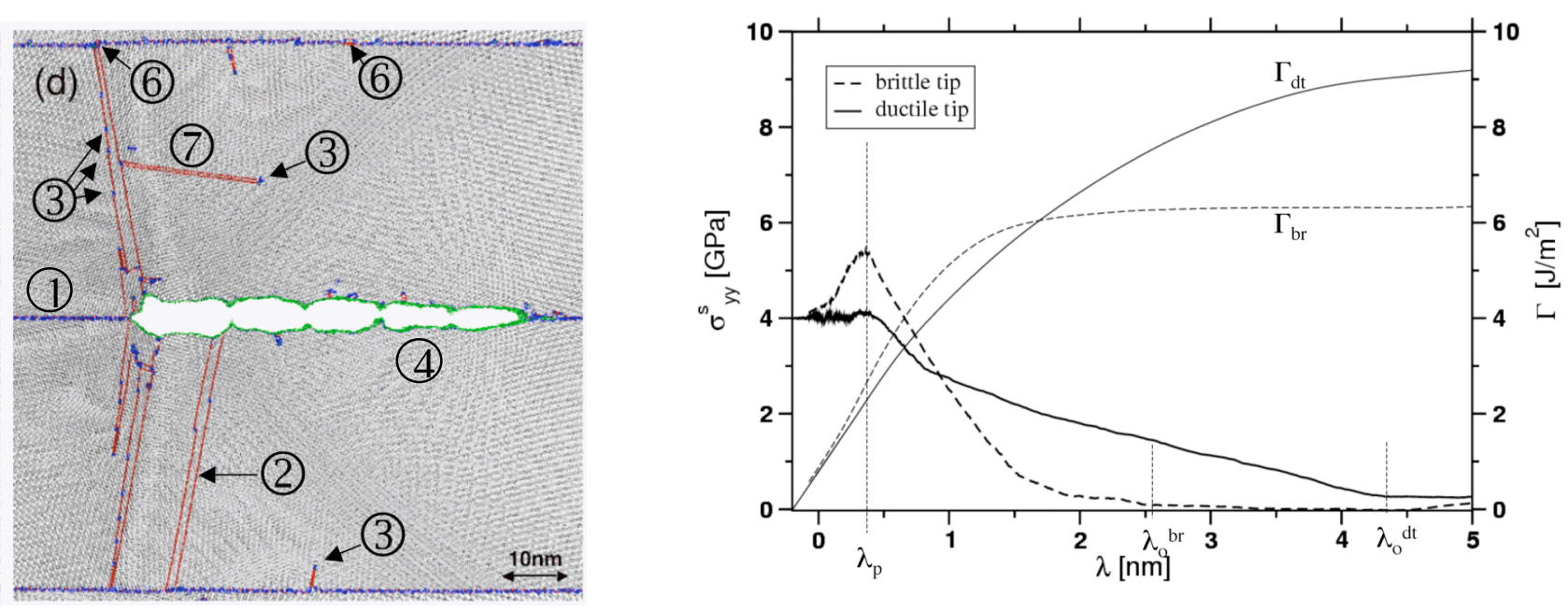

Figure 18: Mechanisms of Nano-Crack Formation and Interfacial Traction-Displacement Relationship

\section{Experimental Damage Science}

Additional insight into the fundamental mechanisms of deformation and fracture is gained by experimental observation of damage growth under extremely high magnification. By integrating the knowledge gained through the computational and experimental interrogation, a true understanding of damage processes may be developed.

Figure 19 shows tools for understanding the processes of crack growth at very small scales. Fracture Surface Topography Analysis (FRASTA) reconstructs the fracture process from three-dimensional topographs of conjugate fracture surfaces. Once the three-dimensional fracture surfaces are mapped, the relative contributions of mode I, II and III to the microscale fracture processes can be understood. Besides providing mechanistic and microstructural information not obtainable from conventional fracture surface examination, FRASTA can often provide the history of a crack's growth and estimate the macroscopic fracture toughness of the material.

An Environmental Scanning Electron Microscope (ESEM) has been equipped with an Electron Backscattered Detector (EBSD) and an in-situ loading frame. This system can be used to determine near crack-tip damage process under various loading conditions and environments, and relate these processes to load, strain and local microstructural features. Secondary electron images will be analyzed with a Digital Image Correlation system designed for this microscope to determine high-resolution displacement measures near a growing crack tip. The system will allow the effect of microstructural details (e.g., grain orientation, grain size, and configuration of defects), environment and loading on damage growth to be determined. Examples of scanning electron micrographs taken near the tip of a propagating crack are shown in Figure 19. 


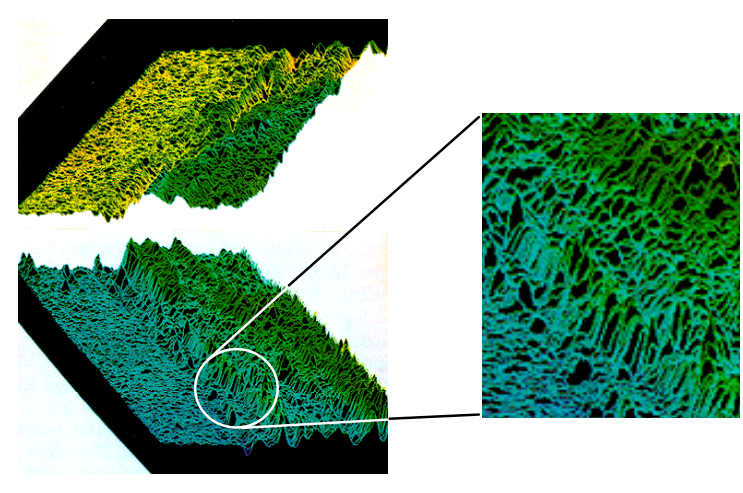

Fracture Surface Topology Analysis

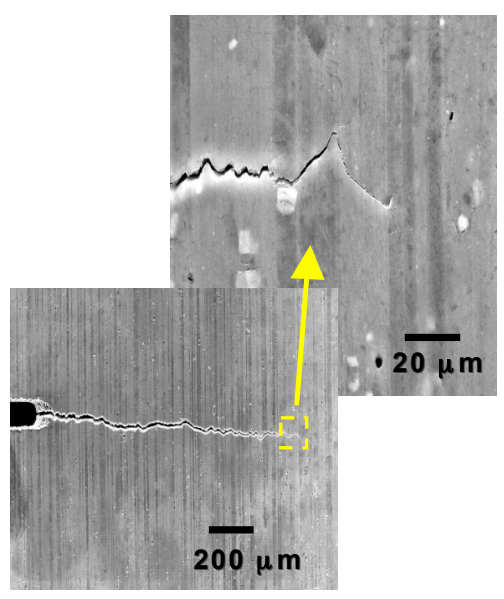

Scanning Electron Microscopy

Figure 19: Experimental Damage Science

\section{Current and Future Requirements}

Innovation in aircraft and spacecraft design continues to increase the demands on aerospace structures and materials. Composite materials have become increasingly more prevalent as primary structures in aircraft and their use in spacecraft is becoming more prominent and is driven primarily by ubiquitous demands for decreased weight. Understandably, the increasing prevalence of composites as load-bearing aerospace structures has created a desire by the manufacturers and designers of metallic materials and structures to reduce their manufacturing cost, part count and structural weight. As a result, the aircraft industry has also begun to consider designs based on the use of novel metallic structures, such as integrally-stiffened aircraft skin panels, that are being developed as successors to traditional riveted skin-stiffened designs.

All too often, the requirements for reduced weight and decreased cost are achieved at the expense of durability and damage tolerance (D\&DT). However, all aerospace vehicles must be designed to be durable and damage tolerant. While this statement appears self-evident to members of the D\&DT community, the implied requirements create numerous challenges for the analysis of structures composed of either composite or metallic materials. Because of the innovative configurations that are being considered by designers and manufacturers of aerospace structures, it is imperative that the durability and damage tolerance (D\&DT) community not only develop more accurate and computationally efficient tools for predicting damage initiation and growth, but that it also dramatically increase the understanding of the fundamental processes that become manifested as structural damage. This is one of the most critical factors in the success of NASA's visions for Aeronautics and Space Exploration.

Consequently, NASA Langely Research Center continues to develop advanced mechanics-based computational and experimental D\&DT methodologies to predict, assess, and understand damage within advanced composite and metallic materials and structures. These D\&DT methodologies must address the deleterious effects of changes in material properties and the initiation and growth of microstructural damage that inevitably occur during the service lifetime of the vehicle. This approach is inherently interdisciplinary and is conducted by combining the disciplines of fracture/damage mechanics, structural mechanics, material science, and physics for the purpose of developing advanced integrated technologies to support the development and assessment of the structural integrity of current and next generation aerospace vehicles.

Additionally, because of uncertainties in structural loads, accepted material properties and configurational details, traditional deterministic aerospace structural design typically relies on factors of safety to assure structural 
integrity. The factor of safety between the design limit load and the design ultimate load conditions is considered to account for uncertainties in parameters such as dimensions, loads and material properties. Thus, structures are designed to carry loads that are substantially greater than the largest loads anticipated, leading, in some cases, to overly conservative designs. The use of non-deterministic methods (e.g., reliability based design methods) promises additional improvements over traditional deterministic design methods by quantifying these uncertainties and accounting for them in the design process. The result of this consideration is the challenging but critical requirement that these methodologies become integrated within the aerospace industry's durability and damage tolerance engineering practices.

\section{Concluding Remarks}

An overview of recent and planned future research in durability and damage tolerance analytical and experimental methods for both metallic and composite aerospace structures has been presented. The current stateof-the-art in computational and experimental methods was illustrated using discussions of recent NASA programs and failure investigations. While the current capabilities have been demonstrated on realistic large-scale structural configurations concomitant to the NASA programs and failure investigations, areas of improvement for both computational and experimental methodologies exist and are needed to increase their level of maturity.

Various levels of detail (e.g. multiscale capabilities) are required to address rigorously the durability and damage tolerance requirements for commercial transport aircraft and NASA spacecraft systems. These multiscale analysis capabilities must facilitate the bridging of the spatial scales and employ an adequate level of understanding of the damage processes without incurring unnecessary expenditure of resources. Moreover, while most of the computational and experimental capabilities have been developed at a low-to-mid technology readiness level (TRL), (i.e., from basic principles to component level application), they are not fully developed for all aerospace applications. Thus, it is imperative that these capabilities be developed further to move to a higher TRL level such that the capabilities are available to the aircraft and spacecraft designer and analysts for general use in industry.

Finally, several general comments can be made regarding the state of durability and damage tolerance practices. First, physics-based and experimentally-validated computational methods are under development that will eventually enable rigorous damage tolerant design and analysis methodology (damage initiation, growth, damage processes, and residual strength) for metallic and composite materials and structures. Second, emerging experimental and computational methods for durability and damage tolerance are necessary to build upon and advance the current state-of-the-art for use in current design practices. Third, satisfying advanced durability and damage tolerance design and analysis requirements is very challenging and requires expertise in failure mechanics, fracture mechanics, structural mechanics, material science, and physics to guide the experimental and analytical work.

\section{References}

1. Harris, C.E., Starnes, J.H. and Shuart, M.J., "Advanced Durability and Damage Tolerance Design and Analysis Methods for Composite Structures," NASA TM 2003-21240, June 2003.

2. Anon., Commercial Aviation Safety Team (CAST) Safety Plan, October 2004.

3. Anon., National Transportation Safety Board Factual Report, NTSB ID: DCA88MA054, June 1990.

4. Harris, C.E., Newman, Jr., J.C., Piascik, R.S. and Starnes, Jr., J.H., "Analytical Methodology for Predicting Widespread Fatigue Damage Onset in Fuselage Structure,” Journal of Aircraft, Vol. 35, No. 2, pp. 307-317, March-April 1998.

5. Anon., National Transportation Safety Board Factual Report, NTSB ID: DCA02MA001, April 2005.

6. Anon., "In-Flight Separation of Vertical Stabilizer American Airlines Flight 587," NTSB Aircraft Accident Report, NTSB/AAR-04/04, 2004.

7. Raju, I.S., Glaessgen, E.H., Mason, B.H., Krishnamurthy, T. and Davila, C.G., "NASA Structural Analysis Report of the American Airlines Flight 587 Accident - Local Analysis of the Right Rear Lug," Proceedings of the 46th AIAA/ASME/ASCE/AHS/ASC Structures, Structural Dynamics, and Materials Conference, AIAA-20052255-CP, AIAA, Austin, TX, April 18-21, 2005.

8. Anon., National Transportation Safety Board Factual Report, NTSB ID: DCA96MA068, March 1998. 
9. Anon., “Uncontained Engine Failure Delta Air Lines Flight 1288," NTSB Aircraft Accident Report, NTSB/AAR98/01, 1998.

10. Anon., NTSB Safety Recommendation, NTSB/A-04-29 through -33, April 2004.

11. Anon., National Transportation Safety Board Factual Report, NTSB ID: LAX02GA201, June 2002.

12. Harris, C.E. and Heyman, J.S., "Overview of NASA Research Related to the Aging Commercial Transportation Fleet," Journal of Aircraft, Vol. 30, No. 1, pp. 64-68, Jan-Feb, 1993.

13. Shivakumar, K. N., and Newman, J. C., Jr., ZIP3D-An Elastic and Elastic-Plastic Finite-Element Analysis Program for Cracked Bodies, NASA TM 102753, 1990.

14. Potyondy, D. O., "A Software Framework for Simulating Curvilinear Crack Growth in Pressurized Thin Shells," Ph.D. Dissertation, Cornell Univ., Ithaca, NY, June 1993.

15. Potyondy, D. O., Wawrzynek, P. A., and Ingraffea, A. R., "'Discrete Crack Growth Analysis Methodology for Through Cracks in Pressurized Fuselage Structures," Proceedings of the FAA/NASA International Symposium on Advanced Structural Integrity Methods for Airframe Durability and Damage Tolerance, edited by C. E. Harris, NASA Langley Research Center, Hampton, VA, 1994, pp. 581 - 602.

16. Brogan, F. A., Rankin, C. C., and Cabiness, H. D., STAGS User Manual, Lockheed Palo Alto Research Lab., Rept. P032594, Palo Alto, CA, 1994.

17. Newman, J. C., Jr., FASTRAN II-A Fatigue Crack Growth Structural Analysis Program, NASA TM 104159, Feb. 1992.

18. Forman, R. G., Shivakumar, V., and Newman, J. C., Jr., Fatigue Crack Growth Computer Program NASA/FLAGRO Version 2.0, NASA JSC-22276A, May 1994.

19. Dawicke, D.S. and Sutton, M.A., Crack-Tip-Opening Angle Measurements and Crack Tunneling Under Stable Tearing in Thin Sheet 2024-T3 Aluminum Alloy, NASA CR 191523, September 1993.

20. Dawicke, D.S., Sutton, M.A., Newman, Jr., J.C. and Bigelow, C.A., Measurement and Analysis of Critical CTOA for an Aluminum Alloy Sheet, NASA TM 109024, September 1993.

21. Sutton, M.A., Dawicke, D.S. and Newman, Jr., J.C., Orientation Effects on the Measurement and Analysis of Critical CTOA in an Aluminum Alloy Sheet, NASA TM 109153, September 1994.

22. Dawicke, D.S., Newman, Jr., J.C. and Bigelow, C.A., Three-Dimensional CTOA and Constraint Effects During Stable Tearing in a Thin-Sheet Material, NASA TM 109183, February 1995.

23. Poe, Jr., C.C. and Harris, C.E., Mechanics of Textile Composites Conference, NASA CP 3311, Parts 1 and 2, October 1995.

24. Wang, J.T., Jegley, D.C., Bush, H.G. and Hinrichs, S.C., Correlation of Structural Analysis and Test Results for the McDonnell Douglas Stitched/RFI All-Composite Wing Stub Box, NASA TM 110267, July 1996.

25. Krueger, R., "Virtual Crack Closure Technique: History, Approach, and Applications," Applied Mechanics Reviews, Vol. 57, pp. 109-143, 2004.

26. Anon., Final Report of the X-33 Liquid Hydrogen Tank Test Investigation Team, National Aeronautics and Space Administration, George C. Marshall Space Flight Center, Huntsville, AL 35812, May 2000.

27. Glaessgen, E.H., Reeder, J.R., Sleight, D.W., Wang, J.T., Raju, I.S. and Harris, C.E., "Debonding Failure of a Sandwich-Composite Cryogenic Fuel Tank with Internal Core Pressure," Journal of Spacecraft and Rockets, Vol. 42, No. 4, 2005, pp. 613-627.

28. Newman, J.A., Riddell, W.T. and Piascik, R.S., Modeling the Interactions Between Multiple Crack Closure Mechanisms at Threshold, NASA TM 2003-212402, May 2003.

29. Newman, J.A., Riddell, W.T. and Piascik, R.S., Analytical and Experimental Study of Near-Threshold Interactions Between Crack Closure Mechanisms, NASA TM 2003-211755, May 2003.

30. Seshadri, B.R. and Smith, S.W., "Three Dimensional Constraint Effects on the Estimated $\triangle$ CTOA During the Numerical Simulation of Different Fatigue Threshold Testing Techniques," Proceedings of the 48th AIAA/ASME/ASCE/AHS/ASC Structures, Structural Dynamics, and Materials Conference, AIAA-2007-2344CP, AIAA, Honolulu, HI, April 23-26, 2007.

31. Seshadri, B.R., Forth, S.C., Johnston, W.M., Domack, M.S. and Newman, Jr., J.C., "Application of CTOA/CTOD in the Residual Strength Analysis of Built-Up and Integral Structures," Presentation at $11^{\text {th }}$ International Conference on Fracture, Turin, Italy, March 20-25, 2005.

32. Krueger, R. and Minguet, P.J., "Composite Skin/Stringer Disbond Analysis Using A Shell/3D Modeling Technique," Proceedings of American Society for Composites, 21 st Annual Technical Conference, Dearborn, Michigan, 2006.

33. Krueger, R. and Minguet, P.J., Analysis of Composite Panel-Stiffener Debonding Using a Shell/3D Modeling Technique, NASA CR 2006-214299, 2006.

34. Krueger, R. and Minguet, P.J., Skin-Stiffener Debond Prediction Based on Computational Fracture Analysis, NASA CR 2005-213915, 2005.

35. Minguet, P.J., Fedro, M.J., O'Brien, T.K., Martin, R.H. and Ilcewicz, L.B. "Development of a Structural Test 
Simulating Pressure Pillowing Effects in Bonded Skin/Stringer/Frame Configuration," Proceedings of the Fourth NASA/DoD Advanced Composite Technology Conference, Salt Lake City, Utah, 1993.

36. Murri, G.B. and Schaff, J.R., "Fatigue Life Methodology for Tapered Hybrid Composite Flexbeams," Composites Science and Technology, Vol. 66, 2006, pp. 499-508.

37. Reeder, J.R., "3-D Mixed Mode Delaminaton Fracture Criteria-An Experimentalists Perspective," Proceedings of the American Society for Composites $21^{\text {st }}$ Annual Technical Conference, Dearborn, MI, September 17-20, 2006.

38. Reeder, J.R., "Refinements to the Mixed-Mode Bending Test for Delamination Toughness," Journal of Composites Technology and Research, Vol. 25, No. 4, pp.191-195, 2003.

39. Knight, Jr., N.F., User-Defined Material Model for Progressive Failure Analysis, NASA CR 2006-214526, December 2006.

40. Turon, A., Dávila, C.G., Camanho, P.P. and Costa, J., "An Engineering Solution for using Coarse Meshes in the Simulation of Delamination with Cohesive Zone Models," NASA TM 2005-213547, 2005.

41. Chang, F.-K., Qing, X., Sun, H.-T., and Yan, Y., Damage Tolerance-Based Design of Bolted Composite Joints, Final Report under Contract No. TZ-370444-07LHN, Department of Aeronautics and Astronautics, Stanford University, 2000.

42. Ratcliffe, J.G., Jackson, W.C. and Schaff, J.R., "Compression Strength Prediction of Impact-Damaged Composite Sandwich Panels," Proceedings of American Helicopter Society Technical Specialists' Meeting on Rotorcraft Structures and Survivability, Baltimore, MD, June 2004.

43. Yamakov, V., Saether, E., Phillips, D.R. and Glaessgen, E.H., "Asymmetric Inter-granular Crack Growth Along $\Sigma 99$ Grain Boundary in Aluminum by Molecular Dynamics and Finite Element Simulations," Journal of the Mechanics and Physics of Solids, Vol. 54, pp. 1899-1928, 2006.

44. Tadmore, E.B. and Hai, S., "A Peierls Criterion for the Onset of Deformation Twinning at a Crack Tip," Journal of the Mechanics and Physics of Solids, Vol. 51, pp. 765-793, 2003. 